\title{
Химический и электрохимический вклады в редокс-сорбцию кислорода из воды на зернистых слоях медьсодержащих нанокомпозитов
}

\author{
(C) 2020 Кравченко Т.А., Вахнин Д.Д., Придорогина В.Е., \\ Шевцова Е.А., Чумакова А.В.
}

Воронежский государственньй университет, Воронеж

Поступила в редакцию 12.07.2020 г.

DOI: $10.17308 /$ sorpchrom.2020.20/2958

Наночастицы металлов в пористых полимерных матрицах проявляют выраженные сорбционные и окислительно-восстановительные свойства. На этих свойствах металл-полимерных нанокомпозитов (НК) основан процесс глубокой деоксигенации воды. Ранее обнаружен существенный вклад электрохимической составляющей процесса восстановления кислорода на тонком катодно поляризуемом зернистом слое медьсодержащего НК. В начальный период процесс лимитируется стадией внешней диффузии кислорода к поверхности гранул НК. В последующем отмечен все возрастающий со временем вклад химической составляющей, характерной особенностью которой является лимитирование процесса внутридиффузионной стадией переноса кислорода к наночастицам меди и затрата электричества на электровосстановление оксидов металла. Однако при переходе от тонких пленок и слоев к зернистым слоям НК колоночного типа с распределенными по высоте кинетическими параметрами вопрос о соотношении вкладов электрохимического и химического маршрутов требует специального рассмотрения.

В настоящей работе исследован процесс редокс-сорбции кислорода из воды на динамических зернистых слоях нанокомпозитов медь-сульфокатионообменник (КУ-23, Lewatit K2620) при различных силах поляризующего тока, оценены вклады химической и электрохимической составляющих общего процесса в стационарный период.

Найдено, что количество поглощенного кислорода находится в экстремальной зависимости от силы поляризующего тока в допредельном режиме поляризации. Отмечено образование продуктов окисления металлических наночастиц в виде островковых кластеров, часть зерен окисляется с возникновением границ оксидных слоев, одинаковых по высоте зернистого слоя. С увеличением высоты зернистого слоя и силы поляризующего тока в допредельном режиме процесс поглощения кислорода становится все более квазистационарным. Показано, что вклады химического и электрохимического маршрутов восстановления кислорода соизмеримы при длительном процессе (100 ч). Часть кислорода поглощается за счет реакции электровосстановления на частицах меди в основном на поверхности зерен нанокомпозита, а часть - за счет автокаталитической химической реакции кислорода с электрорегенерируемыми наночастицами металла в объеме зерен нанокомпозита. Тот или иной механизм более вероятен в зависимости от состояния системы и силы воздействия на нее электрического тока. За счет постоянной электрогенерации ионов водорода и электрорегенерации наночастиц меди, необходимых для восстановления кислорода, устанавливается стационарный режим редокс-сорбции кислорода их воды.

Ключевые слова: нанокомпозит, зернистые слои, кислород, восстановление, электрохимический и химический вклады, автокаталитический механизм.

\section{Введение}

Наночастицы металлов в пористых полимерных матрицах проявляют выраженные сорбционные и окислительно-восстановительные свойства. На этих свой- 
ствах металл-полимерных нанокомпозитов (НК) основан процесс глубокой деоксигенации воды [1-3]. В качестве полимера предлагается использование ионообменного материала. За счет его пористой структуры и функциональных ионогенных групп возможно варьировать размер наночастиц металлов и их содержание. Благоприятствует и водородная форма ионообменной полимерной матрицы, обеспечивающая участие противоионов водорода в реакции восстановления кислорода и сток продуктов окисления - ионов металла на ионогенные центры. Процесс, как правило, лимитируется стадией внутренней диффузии кислорода с некоторым вкладом химической реакции [4]. В результате возможным становится процесс глубокого обескислороживания воды.

Сделать непрерывным этот процесс позволяет электрохимическая поляризация металл-ионообменного НК, благодаря которой основная часть кислорода восстанавливается электрохимически за счет внешнего электрического тока по четырехэлектронному механизму, а довосстановление оставшегося кислорода происходит за счет окисления химически активных наночастиц металла НК в отличие от каталитического способа с участием благородных металлов [5].

Обнаружен существенный вклад электрохимической составляющей процесса восстановления кислорода на тонком катодно поляризуемом зернистом слое медьсодержащего НК. В начальный период процесс лимитируется стадией внешней диффузии кислорода к поверхности гранул НК. В последующем отмечен все возрастающий со временем вклад химической составляющей, характерной особенностью которой является лимитирование процесса внутридиффузионной стадией переноса кислорода к наночастицам меди и затрата электричества на электровосстановление оксидов металла $[6,7]$.

Однако при переходе от тонких пленок и слоев к зернистым слоям НК колоночного типа с распределенными по высоте кинетическими параметрами вопрос о соотношении вкладов электрохимического и химического маршрутов требует рассмотрения. В настоящей работе исследована динамика редокс-сорбции кислорода из воды на катодно поляризуемых зернистых слоях медь-ионообменных НК.

\section{Экспериментальная часть}

Химическим осаждением меди в макропористые сульфокатионообменные матрицы КУ-23 и Lewatit K2620, различающиеся равномерностью распределения пор по размерам, в виде сферических гранул получены НК с содержанием металла 9.6-9.8 мэкв/см³ . Химическое осаждение меди проводилось согласно [4].

Электродинамика редокс-сорбции растворенного в воде кислорода изучалась на зернистом слое заданной высоты в сорбционно-мембранном деоксигенаторе, аналогичном для тонкого слоя [7] с тем отличием, что высота зернистого слоя составляла $L=6 \cdot 10^{-2}$ м, что первоначально обеспечивало существенный градиент концентрации кислорода вдоль слоя. Схема представлена на рис. 1. Сорбционномембранная система состоит из двух анодных отделений с платиновыми анодами, отделенными от катодного пространства катионообменными мембранами МК-40. Токоподвод катода проволочный медный. Анодные отделения загружены сульфокатионообменником КУ-23 или Lewatit K2620 в $\mathrm{H}^{+}$форме. В катодном отделении нанокомпозит металл $\left(\mathrm{Cu}^{0}\right)$ - сульфакатионообменник КУ-23 или Lewatit K2620 в $\mathrm{Na}^{+}$форме. Сечение слоя нанокомпозита $S=1.2 \cdot 10^{-4} \mathrm{~m}^{2}$, дистиллированная вода пропускалась через электролизер снизу вверх с линейной скоростью $u=0.23 \cdot 10^{-2} \mathrm{M} / \mathrm{c}$. Поляризацию системы проводили от источника питания АКИП 1111 (Тайвань) постоянным током. Концентрацию окислителя фиксировали 
анализатором кислорода АКПМ-01 (ООО «Альфа-Бассенс», Россия), экранированным металлической сеткой от внешних электромагнитных полей. Концентрация кислорода в дистиллированной воде поддерживалась постоянной в течение эксперимента посредством непрерывного аэрирования воды атмосферным воздухом. Значение водородного показателя воды на выходе из зернистого слоя НК определяли с помощью иономера АНИОН-4100 (Россия). Значение электропроводности воды фиксировали кондуктометром inoLab Cond 7110 (Германия).

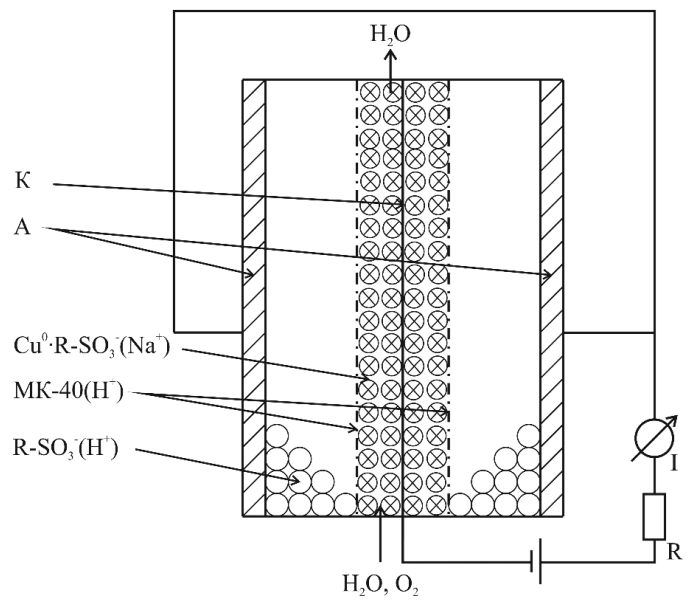

Рис. 1. Схема сорбционно-мембранного деоксигенатора воды высотой $L=6 \cdot 10^{-2} \mathrm{M} . \mathrm{K}$ - катод медный проволочный; A - аноды платиновые проволочные; МК-40 - сульфокатионообменная мембрана в $\mathrm{H}^{+}$-форме; $\mathrm{R}_{-} \mathrm{SO}_{3}^{-}\left(\mathrm{H}^{+}\right)$- гранулированный сульфокатионообменник; $\mathrm{Cu}^{0} \cdot \mathrm{R}_{-} \mathrm{SO}_{3}{ }^{-}\left(\mathrm{Na}^{+}\right)$- нанокомпозит, $\mathrm{I}$ - амперметр, $\mathrm{R}$-переменное сопротивление.

Fig. 1. A scheme of the adsorption-membrane water deoxygenator with the height of $L=6 \cdot 10^{-2} \mathrm{~m}$. K - copper wire cathode; A - platinum wire anodes; MK-40 - sulfocation-exchange membrane in the $\mathrm{H}^{+}$form; $\mathrm{R}-\mathrm{SO}_{3}{ }^{-}\left(\mathrm{H}^{+}\right)$- granular sulfocation exchanger; $\mathrm{Cu}^{0}$ $\mathrm{R}_{-} \mathrm{SO}_{3}{ }^{-}\left(\mathrm{Na}^{+}\right)$- nanocomposite, $\mathrm{I}$ - ammeter, $\mathrm{R}$ - variable resistance.

Для расчета значения задаваемого поляризующего тока на зернистом слое выбранной высоты был использован электрохимический подход [7], согласно которому в гальваностатическом режиме ток распределяется линейно вдоль слоя и ограничивается значением, пропорциональным концентрации кислорода на выходе. Рассчитана сила предельного (максимально допустимого до выделения водорода) тока $I_{\text {lim }}(L)$, которая при заданных условиях эксперимента составила $15.3 \pm 0.2 \mathrm{~mA}$ Исследован допредельный режим поляризации зернистого слоя высотой $L$.

\section{Обсуждение результатов}

Получены выходные кривые для концентрации кислорода, растворенного в воде, прошедшей через зернистый нанокомпозитный слой $\mathrm{Cu}^{0} \cdot \mathrm{KУ}-23\left(\mathrm{Na}^{+}\right)$или $\mathrm{Cu}^{0} \cdot$ Lewatit $\left(\mathrm{Na}^{+}\right)$высотой $L=6 \cdot 10^{-2}$ м в сорбционно-мембранной системе в гальваностатическом режиме катодной поляризации. Продолжительность поляризации составляла 100 ч. Как видно из рис. 2, концентрация кислорода резко падает на выходе из слоя в первые часы проведения эксперимента, затем возрастает и по истечение 50 ч медленно изменяется. Динамический зернистый слой НК немного повышает водородный показатель воды до 6.5-6.8, в то же время электропроводность остается на уровне как у входящей в реактор воды. 


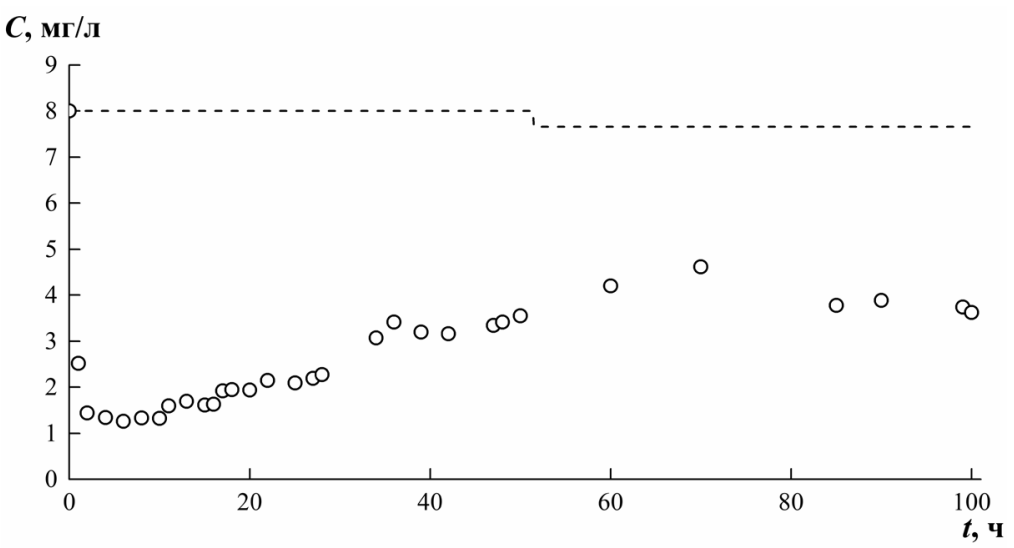

Рис. 2. Динамическая выходная кривая редокс-сорбции кислорода $C-t$, растворенного в воде, на выходе из катодно поляризуемого зернистого слоя нанокомпозита

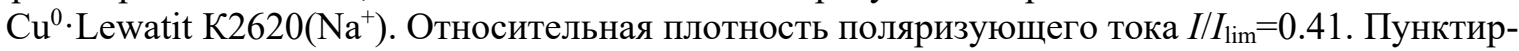
ной линией обозначена концентрация кислорода в исходной воде. Условия эксперимента: $\varepsilon_{\mathrm{Cu}}{ }^{0}=9.6 \mathrm{мэкв} / \mathrm{cm}^{3}, L=6 \cdot 10^{-2} \mathrm{M}, u=0.23 \cdot 10^{-2} \mathrm{м} / \mathrm{c}, C_{0}=8.0 \mathrm{мг} /$ дм$^{3}, I=6.3 \mathrm{мA}$.

Fig. 2. Dynamic diagram of the redox-sorption of oxygen $C-t$ absorbed in water, at the output of the cathode-polarised granular layer of the nanocomposite $\mathrm{Cu}^{0} \cdot$ Lewatit $\mathrm{K} 2620\left(\mathrm{Na}^{+}\right)$. The relative density of the polarising current $I / I_{\mathrm{lim}}=0.41$. The dotted line

denotes the initial oxygen concentration in water. Conditions of the experiment: $\varepsilon_{\mathrm{Cu}}{ }^{0}=9.6 \mathrm{mEq} / \mathrm{cm}^{3}, L=6 \cdot 10^{-2} \mathrm{~m}, u=0.23 \cdot 10^{-2} \mathrm{~m} / \mathrm{s}, C_{0}=8.0 \mathrm{mg} / 1, I=6.3 \mathrm{~mA}$.

Количество поглощенного кислорода закономерно возрастает во времени (рис. 3). Скорость поглощения кислорода выходит практически на постоянный уровень, что говорит о квазистационарности процесса под током. Из сопоставления количества кислорода, восстановленного в эксперименте, и рассчитанного по закону Фарадея, можно видеть, что к электрохимическому добавляется еще и химический маршрут, представляющий собой процесс восстановления кислорода за счет окисления наночастиц меди.

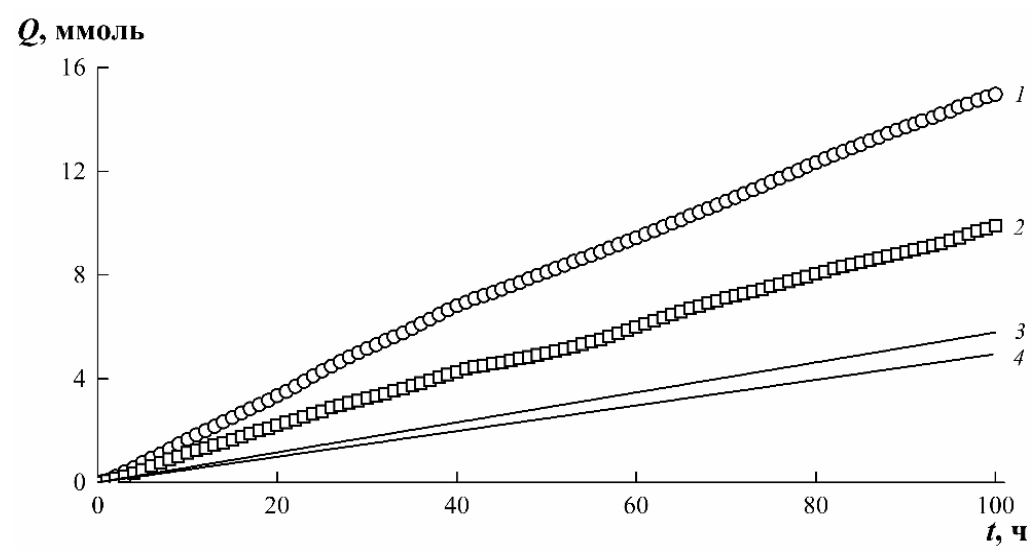

Рис. 3. Количество поглощенного кислорода $Q$ из воды нанокомпозитами $\mathrm{Cu}^{0} \cdot$ Lewatit $\mathrm{K} 2620\left(\mathrm{Na}^{+}\right)$и $\mathrm{Cu}^{0} \cdot \mathrm{KV}-23\left(\mathrm{Na}^{+}\right): 1-\mathrm{Cu}^{0} \cdot$ Lewatit $\mathrm{K} 2620\left(\mathrm{Na}^{+}\right), R_{0}=0.028 \mathrm{cм}, C_{0}=8.0 \mathrm{мг} /$ дм $^{3}, I=6.3$ мА, $2-\mathrm{Cu}^{0} \cdot \mathrm{KУ}-23\left(\mathrm{Na}^{+}\right), R_{0}=0.035 \mathrm{~cm}, C_{0}=6.6 \mathrm{мг} /$ дм$^{3}, I=5.3 \mathrm{MA}, 3$ и 4 - рассчитанные по закону Фарадея для $\mathrm{Cu}^{0} \cdot$ Lewatit $\mathrm{K} 2620\left(\mathrm{Na}^{+}\right)$и $\mathrm{Cu}^{0} \cdot \mathrm{KV}-23\left(\mathrm{Na}^{+}\right)$соответственно.

Fig. 3. The amount of oxygen $Q$ absorbed from water by nanocomposites $\mathrm{Cu}^{0}$. Lewatit $\mathrm{K} 2620\left(\mathrm{Na}^{+}\right)$and $\mathrm{Cu}^{0} \cdot \mathrm{KV}-23\left(\mathrm{Na}^{+}\right): 1-\mathrm{Cu}^{0} \cdot$ Lewatit $\mathrm{K} 2620\left(\mathrm{Na}^{+}\right), R_{0}=0.028 \mathrm{~cm}, C_{0}=8.0 \mathrm{mg} / 1, I=6.3$ $\mathrm{mA}, 2-\mathrm{Cu}^{0} \cdot \mathrm{KV}-23\left(\mathrm{Na}^{+}\right), R_{0}=0.035 \mathrm{~cm}, C_{0}=6.6 \mathrm{mg} / 1, I=5.3 \mathrm{~mA}$,

3 and 4 were calculated using Faraday's law for $\mathrm{Cu}^{0} \cdot$ Lewatit $\mathrm{K} 2620\left(\mathrm{Na}^{+}\right)$and $\mathrm{Cu}^{0} \cdot \mathrm{KV}-23\left(\mathrm{Na}^{+}\right)$ respectively. 
Сводные данные по количеству восстановленного кислорода $Q$ в процессе редокс-сорбции на зернистом слое высотой $L=6 \cdot 10^{-2}$ м при различных плотностях тока приведены на рис. 4. Зависимость количества поглощенного кислорода от тока имеет экстремальный вид, причем со временем максимум все более выражен. При высоких токах проявляется электровосстановление окисленных частиц меди в допредельной области поляризации [8].

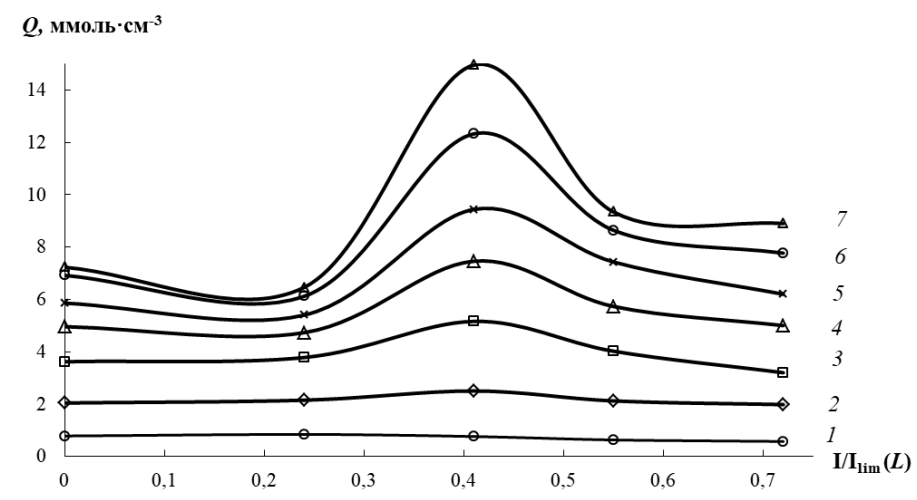

Рис. 4. Зависимость количества восстановленного кислорода из воды нанокомпозитом $\mathrm{Cu}^{0} \cdot$ Lewatit K2620(Na $\left.{ }^{+}\right)$от $I / I_{\text {lim }}(L)$ в момент времени $t$, ч: $1-5 ; 2-15 ; 3-30 ; 4-45$; $5-60,6-80 ; 7-100$. Условия эксперимента: $L=6 \cdot 10^{-2} \mathrm{M}, u=0.23 \cdot 10^{-2} \mathrm{~m} / \mathrm{c}, C_{0}=8.0 \mathrm{Mг} /$ дм $^{3}$.

Fig. 4. Dependence of the oxygen reduced from water by the nanocomposite $\mathrm{Cu}^{0} \cdot$ Lewatit $\mathrm{K} 2620\left(\mathrm{Na}^{+}\right)$on $I / I_{\lim }(L)$ at the moment $t, \mathrm{~h}: 1-5 ; 2-15 ; 3-30 ; 4-45 ; 5-60,6-80 ; 7-100$. Conditions of the experiment: $L=6 \cdot 10^{-2} \mathrm{~m}, u=0.23 \cdot 10^{-2} \mathrm{~m} / \mathrm{s}, C_{0}=8.0 \mathrm{mg} / 1$.

Об этом же свидетельствуют исследования электрокаталитической активности наноструктурированных частиц меди, осажденных в сульфокатионообменную пленку Nafion. Авторы [9] отмечают, что максимум катодного тока, наблюдаемого во время восстановления кислорода, включает в себя ток, обусловленный восстановлением оксида меди $\left(\mathrm{Cu}_{2} \mathrm{O}\right)$, если он присутствует, до $\mathrm{Cu}^{0}$. Основной вклад в ток максимума вносит каталитическая реакция восстановления кислорода.

Для оценки вкладов химического $\omega_{\mathrm{x}}$ и электрохимического $\omega_{э x}$ восстановления кислорода после эксперимента был проведен микроскопический анализ срезов зерен НК. Сплошной зернистый слой был разделялен на 6 равных тонких слоев, из которых отбирались зерна для послойного анализа. Стоит отметить, что в условиях отсутствия внешней поляризации медь нанокомпозита $\mathrm{Cu}^{0}$. Lewatit $\mathrm{K} 2620\left(\mathrm{Na}^{+}\right)$окисляется равномерно с образованием значительного количества зерен (56\%) с четко наблюдаемыми границами парциальных реакций образования оксидов металла. При этом по высоте слоя отмечается рост числа гранул с границами реакций. Количество зерен с новообразованиями составляет $15 \%$. Отличительной особенностью системы при наложении катодной поляризации служит нарушение границ. Для $\mathrm{Cu}^{0} \cdot \mathrm{KУ}$ 23( $\left.\mathrm{Na}^{+}\right)$наблюдается 43\% зерен с границами, 33\% с «островковыми» новообразованиями. Несмотря на объемное окисление меди композита, процесс протекает неравномерно по радиальным направлениям среза, что обусловлено отсутствием тесного контакта зерен нанокомпозита между собой.

Полученные экспериментальные данные пространственных координат $\xi_{1}$ $\left(\mathrm{Cu} / \mathrm{Cu}_{2} \mathrm{O}\right)$ и $\xi_{2}\left(\mathrm{Cu}_{2} \mathrm{O} / \mathrm{CuO}\right)$ при катодной поляризации зернистого слоя медьсодержащих нанокомпозитов представлены на рис. 5. Предположительно, равномерное распространение фронтов реакций можно объяснить тем, что поступающий на колонку окислитель в большей мере восстанавливается в лобовой части насыпного слоя НК, а на выходной слой приходится остаточное количество кислорода. Вслед- 
ствие этого в лобовой части слоя оксид меди $\mathrm{Cu}_{2} \mathrm{O}$ образуется с более высокой скоростью, чем в слое на выходе. Из-за постепенного накопления $\mathrm{Cu}_{2} \mathrm{O}$ химическая активность нанокомпозита снижается.
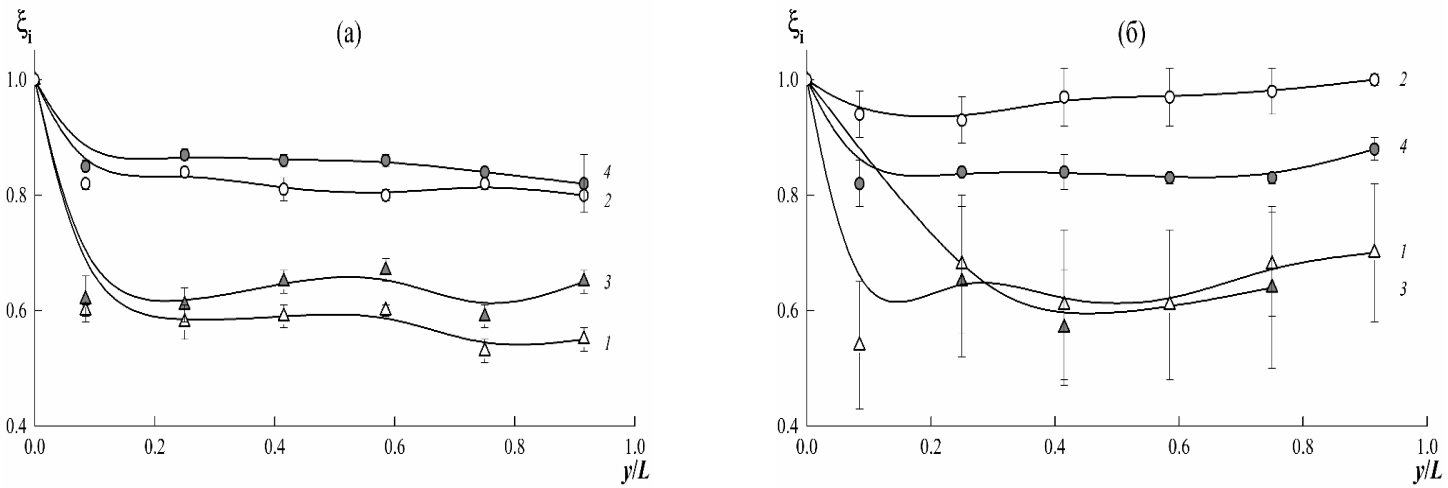

Рис. 5 Динамические кривые для пространственных координат $\xi_{1}\left(\mathrm{Cu} / \mathrm{Cu}_{2} \mathrm{O}\right)$ и $\xi_{2}$

$\left(\mathrm{Cu}_{2} \mathrm{O} / \mathrm{CuO}\right)$ стадийного окисления нанокомпозитов по слою $y$ (от лобового до выходного), отнесенному к высоте всего зернистого слоя $L$ : (а) $-\mathrm{Cu}^{0} \cdot \mathrm{KV}^{2}-23\left(\mathrm{Na}^{+}\right)$; (б) - $\mathrm{Cu}^{0} \cdot$ Lewatit $\mathrm{K} 2620\left(\mathrm{Na}^{+}\right)$. Время эксперимента 100 ч. Кривые: а) $1-\xi_{1}, I=0 \mathrm{мA} ; 2-\xi_{2}, I=0 \mathrm{мA} ; 3-\xi_{1}$, $I=5.3 \mathrm{мA} ; 4-\xi_{2}, I=5.3 \mathrm{мA}$; б) $I-\xi_{1}, I=0 \mathrm{~mA} ; 2-\xi_{2}, I=0 \mathrm{~mA} ; 3-\xi_{1}, I=6.3 \mathrm{мA} ; 4-\xi_{2}, I=6.3 \mathrm{~mA}$.

Fig. 5 Dynamic curves for spatial coordinates $\xi_{1}\left(\mathrm{Cu} / \mathrm{Cu}_{2} \mathrm{O}\right)$ and $\xi_{2}\left(\mathrm{Cu}_{2} \mathrm{O} / \mathrm{CuO}\right)$ of the stage oxidation of the nanocomposites in the layer $y$ (from the front to the output), assigned to the height of the whole granular layer $L$ : (a) $-\mathrm{Cu}^{0} \cdot \mathrm{KY}-23\left(\mathrm{Na}^{+}\right)$; (b) $-\mathrm{Cu}^{0} \cdot$ Lewatit $\mathrm{K} 2620\left(\mathrm{Na}^{+}\right)$. The experiment lasted 100 hours. Curves: a) $I-\xi_{1}, I=0 \mathrm{~mA} ; 2-\xi_{2}, I=0 \mathrm{~mA} ; 3-\xi_{1}, I=5.3 \mathrm{~mA} ; 4-\xi_{2}, I=5.3 \mathrm{~mA}$; b) $I-\xi_{1}, I=0 \mathrm{~mA} ; 2-\xi_{2}, I=0 \mathrm{~mA} ; 3-\xi_{1}, I=6.3 \mathrm{~mA} ; 4-\xi_{2}, I=6.3 \mathrm{~mA}$.

Как было показано в [8], электрический ток при катодной поляризации неравномерно окисленного композита распределяется по высоте зернистого слоя таким образом, чтобы устранить возникающее в процессе редокс-сорбции изменение химической активности нанокомпозита, т.е. расходуется в основном на восстановление оксида меди, а кислород при этом преимущественно восстанавливается химическим путем взаимодействия с металлом. В результате степень окисления НК становится примерно одинаковой по всей высоте слоя. Таким образом, химическая активность композита выравнивается, что и наблюдается по постоянному распространению границ последовательных химических реакций образования оксидов меди. Система стремится выйти в квазистационарный режим.

Материальный баланс и вклады химической и электрохимической компонент восстановления кислорода приведены в табл. 1 и 2 . Количество восстановленного кислорода $Q$ было найдено из динамических зависимостей концентрации кислорода на выходе из электролизера, $Q_{\text {хим}}(\xi)$ рассчитано с учетом координат $\xi$ парциальных

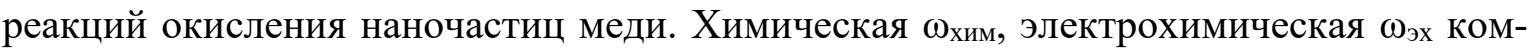
поненты процесса восстановления кислорода, а также доля тока $\eta_{\mathrm{T}}$ (окс), израсходованного на электрорегенерацию наночастиц меди, были рассчитаны согласно [7].

Экспериментальные результаты на зернистом слое НК в стационарный период редокс-сорбции кислорода свидетельствуют о значительном вкладе химической стадии восстановления кислорода наночастицами меди, что дает основание предположить автокаталитический механизм процесса.

В анодных отделениях под действием внешнего тока происходит разложение воды с выделением газообразного кислорода и ионов водорода:

$$
2 \mathrm{H}_{2} \mathrm{O} \rightarrow \mathrm{O}_{2}+4 \mathrm{H}^{+}+4 \mathrm{e}^{-}
$$

Дальнейший транспорт образующихся ионов водорода происходит под действием электрического поля путем перемещения по ионогенным группам сульфока- 
тионообменника в катодное отделение, где они участвуют в эквивалентном количестве в реакции

$$
\mathrm{O}_{2}+4 \mathrm{H}^{+}+4 \mathrm{e}^{-} \rightarrow 2 \mathrm{H}_{2} \mathrm{O}
$$

Таблица 1. Материальный баланс в процессе электровосстановления молекулярного кислорода тонким зернистым слоем $\mathrm{Cu}^{0}$. Lewatit $\mathrm{K} 2620\left(\mathrm{Na}^{+}\right)$и $\mathrm{Cu}^{0} \cdot \mathrm{KУ}-23\left(\mathrm{Na}^{+}\right)$при

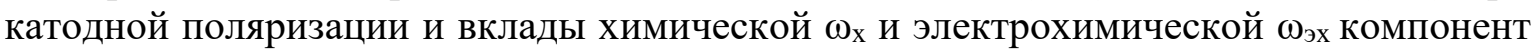
процесса восстановления кислорода. Время эксперимента 100 ч.

Table 1. Material balance during the electroreduction of molecular oxygen by a thin granular layer of $\mathrm{Cu}^{0} \cdot$ Lewatit $\mathrm{K} 2620\left(\mathrm{Na}^{+}\right)$and $\mathrm{Cu}^{0} \cdot \mathrm{KU}-23\left(\mathrm{Na}^{+}\right)$using cathodic polarisation and the contributions of the chemical $\omega_{\mathrm{ch}}$ and electrochemical $\omega_{\mathrm{elch}}$ components of the oxygen reduction process. The experiment lasted 100 hours.

\begin{tabular}{|c|c|c|c|c|c|c|}
\hline \multirow{2}{*}{$\begin{array}{c}\text { Сила по- } \\
\text { ляризую- } \\
\text { щего тока } \\
\text { I, мА }\end{array}$} & \multirow[b]{2}{*}{$I / I_{\lim }$} & \multicolumn{3}{|c|}{$\begin{array}{c}\text { Количество восстановленного кислорода } \\
O, \text { ммоль }\end{array}$} & \multirow[b]{2}{*}{$\omega_{\mathrm{x}}, \%$} & \multirow[b]{2}{*}{$\omega_{\text {эх }}, \%$} \\
\hline & & $\begin{array}{c}\text { Экспери- } \\
\text { ментально } \\
Q \\
\end{array}$ & $\begin{array}{c}\text { Химически } \\
Q_{x}\end{array}$ & $\begin{array}{c}\text { Электро- } \\
\text { химически } \\
Q_{\ni x} \\
\end{array}$ & & \\
\hline \multicolumn{7}{|c|}{$\mathrm{Cu}^{0} \cdot$ Lewatit K2620 $\left(\mathrm{Na}^{+}\right)$} \\
\hline 3.7 & 0.24 & 6.51 & 3.52 & 2.99 & 54.1 & 45.9 \\
\hline 6.3 & 0.41 & 14.96 & 5.40 & 9.56 & 36.1 & 63.9 \\
\hline 8.6 & 0.55 & 9.34 & 2.38 & 6.96 & 25.5 & 75.5 \\
\hline 11.1 & 0.72 & 8.90 & 3.59 & 5.31 & 40.3 & 59.7 \\
\hline \multicolumn{7}{|c|}{$\mathrm{Cu}^{0} \cdot \mathrm{K} Y-23\left(\mathrm{Na}^{+}\right)$} \\
\hline 5.3 & 0.34 & 9.47 & 4.62 & 4.85 & 48.8 & 51.2 \\
\hline
\end{tabular}

Таблица 2. Выход по току для кислорода $\eta_{\mathrm{T}}\left(\mathrm{O}_{2}\right)$ и оксидов меди $\eta_{\mathrm{T}}($ окс $)$ на $\mathrm{Cu}^{0} \cdot$ Lewatit $\mathrm{K} 2620\left(\mathrm{Na}^{+}\right)$и $\mathrm{Cu}^{0} \cdot \mathrm{KУ}-23\left(\mathrm{Na}^{+}\right)$. Время эксперимента 100 ч.

Table 2. Current efficiency for oxygen $\eta_{\mathrm{T}}\left(\mathrm{O}_{2}\right)$ and copper oxides $\eta_{\mathrm{T}}(\mathrm{ox})$ on $\mathrm{Cu}^{0}$. Lewatit $\mathrm{K} 2620\left(\mathrm{Na}^{+}\right)$and $\mathrm{Cu}^{0} \cdot \mathrm{KU}-23\left(\mathrm{Na}^{+}\right)$. The experiment lasted 100 hours.

\begin{tabular}{|c|c|c|c|c|c|}
\hline $\begin{array}{l}\text { Сила поляризую- } \\
\text { щего тока - I, мА }\end{array}$ & $I / I_{l i m}$ & $q$, Кл & $q\left(\mathrm{O}_{2}\right)$, Кл & $\eta_{\mathrm{T}}\left(\mathrm{O}_{2}\right), \%$ & $\eta_{\mathrm{T}}(\mathrm{o \kappa c}), \%$ \\
\hline \multicolumn{6}{|c|}{$\mathrm{Cu}^{0} \cdot$ Lewatit K2620 $\left(\mathrm{Na}^{+}\right)$} \\
\hline 3.7 & 0.24 & 1332 & 1154 & 86.64 & 13.36 \\
\hline 6.2 & 0.41 & 2232 & 3690 & - & - \\
\hline 8.6 & 0.55 & 3096 & 2686 & 86.76 & 13.24 \\
\hline 11.1 & 0.72 & 3996 & 2049 & 51.28 & 48.72 \\
\hline \multicolumn{6}{|c|}{$\mathrm{Cu}^{0} \cdot \mathrm{K} \mathrm{Y}-23\left(\mathrm{Na}^{+}\right)$} \\
\hline 5.3 & 0.34 & 1908 & 1872 & 98.1 & 1.9 \\
\hline
\end{tabular}

Кислород также может химически взаимодействовать с наночастицами меди нанокомпозита, окисляя их. В случае натриевой формы сульфокатионообменной матрицы восстановление кислорода в порах ионообменной матрицы протекает с образованием гидроксидных групп нейтрализуемых в полуреакциях окисления наночастиц меди,

$$
\begin{aligned}
& \mathrm{O}_{2}+2 \mathrm{H}_{2} \mathrm{O}+4 \mathrm{e}^{-} \rightarrow 4 \mathrm{OH}^{-} \\
& 2 \mathrm{Cu}+2 \mathrm{OH}^{-} \rightarrow \mathrm{Cu}_{2} \mathrm{O}+\mathrm{H}_{2} \mathrm{O}+2 \mathrm{e}^{-} \\
& \mathrm{Cu}_{2} \mathrm{O}+2 \mathrm{OH}^{-} \rightarrow 2 \mathrm{CuO}+\mathrm{H}_{2} \mathrm{O}+2 \mathrm{e}^{-}
\end{aligned}
$$

Однако при катодной поляризации оксиды меди наряду с кислородом могут принимать участие в катодном процессе, восстанавливаясь за счет тока до наночастиц свежевосстановленной химически активной меди $\mathrm{Cu}^{*}$,

$$
\mathrm{CuO}+\mathrm{H}_{2} \mathrm{O}+2 \mathrm{e}^{-} \rightarrow \mathrm{Cu}_{2} \mathrm{O}+\mathrm{H}_{2} \mathrm{O}+2 \mathrm{e}^{-} \rightarrow 2 \mathrm{Cu}^{*}+2 \mathrm{OH}^{-}
$$


Схема такого процесса представлена на рис. 6. Процесс поглощения кислорода может лимитироваться внешней диффузией к поверхности зерен нанокомпозита, т.е. имеет место прямое электрохимическое восстановление кислорода, в котором наночастицы меди выступают в качестве катализатора. В том, что эта стадия вероятна и локализована на поверхности зерен, свидетельствуют исследования на тонком зернистом слое [7].

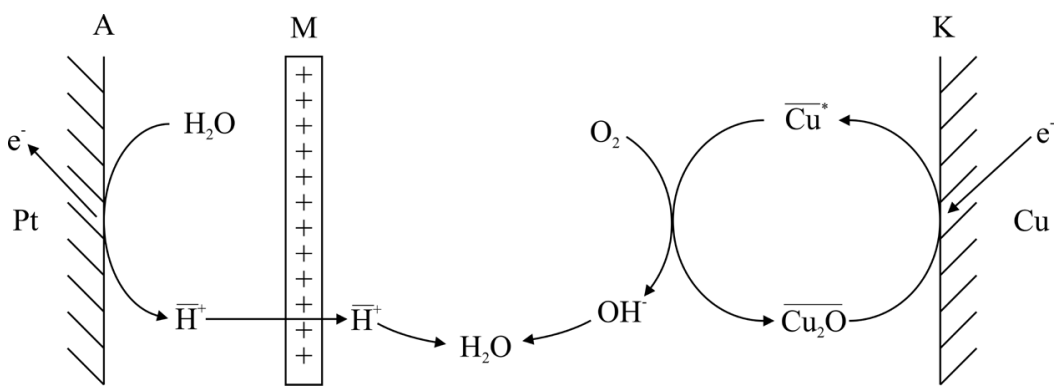

Рис. 6. Пространственная схема автокаталитического процесса восстановления кислорода на катодно поляризованном медь-ионообменном нанокомпозите:

А - анод, М - ионообменная мембрана, К - катод. Черта над символом означает принадлежность к ионообменной матрице.

Fig. 6. 3D configuration of the autocatalytic reaction of oxygen reduction on the cathodepolarised copper - ion-exchange nanocomposite: $\mathrm{A}$ - anode, $\mathrm{M}$ - ion-exchange membrane, $\mathrm{K}$ - cathode. The dash above the symbol denotes the belonging to the ion-exchange matrix.

Тот или иной механизм вероятен в зависимости от состояния системы и силы воздействия на нее электрического тока. Учитывая высокую химическую активность наночастиц меди, можно допустить ее участие в автокаталитическом химическом восстановлении кислорода, в котором окисленные частицы меди непрерывно катодно регенерируются с образованием свежевосстановленных активных центров. В основной период скорость окисления наночастиц соизмерима со скоростью их электровосстановления, за счет чего устанавливается автокаталитический стационарный режим поглощения кислорода в целом.

\section{Заключение}

Установлено влияние электрического тока на скорость поглощения кислорода с помощью динамических зернистых слоев нанокомпозитов. С ростом тока растет количество поглощенного кислорода, дополнительное электровосстановление продуктов окисления снижает скорость целевого процесса. По высоте зернистого слоя нанокомпозита наблюдается резкое продвижение фронтов химических реакций стадийного окисления наночастиц металла к центру зерна с их последующим стабилизированным распространением. Поляризующий ток распределяется по высоте таким образом, чтобы нивелировать разницу в химической активности различных слоев композита. Данное обстоятельство обусловливает распространения границ последовательных химических реакций постоянство скорости образования оксидов меди, а также неизменность скорости поглощения кислорода с течением времени, т.е. стремление системы выйти на квазистационарный режим.

В основе наблюдаемых явлений лежат сопряженные процессы ионного переноса, сорбции, электрохимического и химического восстановления кислорода, химического окисления и электрохимического восстановления наночастиц меди. Предложен механизм редокс-сорбции кислорода из воды на металл-ионообменном нанокомпозите, включающий реакцию электрохимического восстановления кисло- 
рода с участием анодно генерируемых противоионов водорода и химического восстановления кислорода с катодно регенерируемыми наночастицами металла. На стационарном уровне скорость окисления наночастиц соизмерима со скоростью их электрорегенерации.

За счет постоянной электрогенерации ионов водорода и электрорегенерации наночастиц меди, необходимых для восстановления кислорода, устанавливается стационарный режим редокс-сорбции кислорода их воды.

\title{
Исследования поддержаны Российским фондом фундаментальных исследований (код проекта 20-08-00404а).
}

\section{Список литературы}

1. Gross M.S., Pisarello M.L.,Pierpauli K.A.,Querini C.A // J. of Industrial and Engineering Chem. Research. 2010. Vol. 49. pp. 8188. DOI: 10.1021/ie9007369

2. Волков В.В., Кравченко Т.А., Ролдугин В.И. // Успехи химии. 2013. Т. 82. № 5. С. 465-482.

3. Гурский В.С., Кирпиков Д.А., Харитонова Е.Ю. и др. // Журнал прикладной химии. 2015. Т. 88. Вып. 10. С. 1473-1477.

4. Кравченко Т.А., Полянский Л.Н., Калиничев А.И. и др. Нанокомпозиты металлионообменник. М. Наука. 2009. 391 с.
5. Кравченко Т.А., Золотухина Е.В., Чайка М.Ю. и др. Электрохимия нанокомпозитов металл-ионообменник. М.: Наука. 2013.365 с.

6. Вахнин Д.Д., Полянский Л.Н., Кравченко Т.А. и др. // Журн. физич. химии. 2019. Т. 93. № 5. C. 749-756.

7. Кравченко Т.А., Вахнин Д.Д., Чумакова А.В., Шевцова Е.А. // Сорбиионные и хроматографические прочессы. 2020. Т. 20. № 4. C. 434-444.

8. Слепцова О.В., Соцкая Н.В., Кравченко Т.А. // Журн. физич. химии. 1997. Т. 71. № 10. C. $1899-1904$.

9. Selvaraju T., Ramaraj R. // J. Phys. 2005. Vol. 65. No 4. pp. 713-722.

\section{Chemical and electrochemical contributions to the redox-sorption of oxygen from water on granular layers of copper-containing nanocomposites}

\author{
(C) 2020 Kravchenko T.A., Vakhnin D.D., Pridorogina V.E., \\ Shvetsova E.A., Chumakova A.V. \\ Voronezh State University, Voronezh
}

\begin{abstract}
Metal nanoparticles demonstrate noticeable sorption and redox properties in porous polymer matrices. Deep deoxygenation of water is based on these properties of metal-polymer nanocomposites (NC). Earlier studies demonstrated a significant contribution of the electrochemical component to the process of oxygen reduction on a thin cathode-polarised granular layer of a copper-containing nanocomposite. During the early stage, the process is limited by the stage of external diffusion of oxygen towards the surface of the nanocomposite's granules. Further process is marked by the growing contribution of the chemical component. The characteristic feature of this component is that it limits the process by means of internal diffusion stage of oxygen transfer to copper nanoparticles and uses electric current for the electroreduction of metal oxides. However, when transferring from thin films and layers to granular layers of an $\mathrm{NC}$ of the column type with vertically distributed kinetic parameters, the proportion of electrochemical and chemical contributions should be studied further.

In our study, we investigated the redox-sorption of oxygen from water on dynamic granular layers of copper - sulfocation exchanger nanocomposites (KU-23, Lewatit K2620) at various polarisation currents and evaluated the contributions of the chemical and electrochemical components to the stationary period.
\end{abstract}


We determined that the amount of absorbed oxygen depends extremely on the strength of the polarisation current of the limiting polarisation. The products of the metal nanoparticles oxidation were observed in the form of island clusters. The oxidation of some granules is accompanied by the formation of the boundaries of oxide layers of the same height as the granular layer. The higher the granular layer and the stronger the limiting polarising current, the more quasistationary the oxygen absorption process is. The study also demonstrated that the contributions of the chemical and electrochemical paths of the oxygen reduction are compatible, when the process lasts long (100 hours). Some oxygen is absorbed through the reaction of electroreduction on copper particles mainly on the surface of the granules of the nanocomposite. The rest is absorbed by means of an autocatalytic chemical reaction of oxygen with electro-regenerated metal nanoparticles contained in the nanocomposite granules. The probability of each process depends on the state of the system and the current strength. The stationary mode of redox-sorption of oxygen from water is established due to the constant electro-generation of hydrogen ions and electro-regeneration of copper nanoparticles required for the reduction of oxygen.

Keywords: nanocomposite, granular layers, oxygen, reduction, electrochemical and chemical contribution, autocatalytic reaction

\section{References}

1. Gross M.S., Pisarello M.L., Pierpauli K.A., Querini C.A., J. of Industrial and Engineering Chem. Research, 2010, Vol. 49, pp. 81-88. DOI: 10.1021/ie9007369

2. Volkov V.V., Kravchenko T.A., Roldughin V.I., Chemical Review, 2013, Vol. 82, No 5, pp. 465-482.

DOI:10.1070/RC2013v082n05ABEH004325

3. Gurskij V.S., Kirpikov D.A., Haritonova E.Ju. et al., Zhurnal prikladnoj khimii, 2015, Vol. 88, No 10, pp. 1473-1477.

4. Kravchenko T.A., Polyanskii L.N., Kalinichev A.I. et al. Nanokompozity metallionoobmennik. M., Nauka, 2009, 391 p.

Кравченко Тамара Александровна - д.х.н., проф., кафедра физической химии, Воронежский государственный университет, Воронеж

Вахнин Дмитрий Дмитриевич - аспирант, кафедра физической химии, Воронежский государственный университет, Воронеж

Придорогина Валерия Евгеньевна - магистр, кафедра физической химии, Воронежский государственный университет, Воронеж

Шевцова Екатерина Александровна - магистр, кафедра физической химии, Воронежский государственный университет, Воронеж

Чумакова Алина Витальевна - магистр, кафедра физической химии, Воронежский государственный университет, Воронеж
5. Kravchenko T.A., Zolotuhina E.V., Chaika M.Ju. et al., Elektrokhimija nanokompozitov metall-ionoobmennik, M., Nauka, 2013, 365 p.

6. Vakhnin D.D., Polyanskii L.N., Kravchenko T.A. et al., Russ. J. Phys. Chem. A, 2019, Vol. 93, No 5, pp. 951-957. DOI:10.1134/s0044453719050315

7. Kravchenko T.A., Vakhnin D.D., Chumakova A.V. et al., Sorbtsionnye i khromatograficheskie protsessy, 2020, Vol. 20, No 4, pp. 434-444.

8. Slepcova O.V., Sockaja N.V., Kravchenko T.A., Zhurn. fizich. khimii, (in Russian) 1997, Vol. 71, No 10, pp. 1899-1904.

9. Selvaraju T., Ramaraj R., Pramana - J. Phys., 2005, Vol. 65, No 4, pp. 713-722.

Kravchenko Tamara A. - PHD of chemistry, prof. Phsical Chemistry Department, Voronezh State University, Voronezh. E-mail: krav280937@yandex.ru

Vakhnin Dmitrii D. - graduate student of Phsical Chemistry Department, Voronezh State University, Voronezh. E-mail: vakhnin.dima@rambler.ru

Pridorogina Valeria E. - magister of Phsical Chemistry Department, Voronezh State University, Voronezh. E-mail: valerya.2010@yandex.ru

Shevtsova Ekaterina A. - magister of Phsical Chemistry Department, Voronezh State University, Voronezh. E-mail: ekaterina10150@yandex.ru

Chumakova Alina V. - magister of Phsical Chemistry Department, Voronezh State University, Voronezh. E-mail: 7632111@rambler.ru 